\title{
Los Campos Elíseos de Zaragoza: un sitio de recreo urbano para la sociedad decimonónica
}

\author{
Mónica Vázquez Astorga* \\ Universidad de Zaragoza \\ mvazquez@unizar.es
}

RESUMEN: En este texto nos centramos en el estudio de los Campos Elíseos de Zaragoza, que fue un lugar de recreo público establecido en 1868 en el paseo de Torrero (actual paseo de Sagasta), cerca del puente del río Huerva, teniendo como referencia los instalados en otras ciudades europeas en esa centuria. Fue concebido como un espacio para la diversión y sociabilidad cívicas, en el que se ofrecía una amplia variedad de espectáculos y formas de entretenimiento que eran la moda de ese momento: conciertos, obras de teatro, zarzuelas, bailes y áreas de paseo. Igualmente, fue un elemento indispensable en el proceso de construcción de modernidad urbana en esta ciudad. Su desaparición tuvo lugar a finales del siglo XIX, aunque su terreno fue utilizado para otros fines hasta la década de los treinta cuando se proyectó el edificio Elíseos (paseo de Sagasta, núms. 2 y 4, esquina con Gran Vía, núms. 1 y 3).

PALABRAS CLAVE: Campos Elíseos; Zaragoza; Urbanismo del siglo XIX; Jardín de recreo; Velódromo.

\section{The Champs Elysées of Zaragoza: an Urban Recreation Site for Nineteenth-Century Society}

ABSTRACT: In this text we study the Champs Elysées in Zaragoza, which was a public pleasure ground established in 1868 in the paseo de Torrero (present day paseo de Sagasta), near the bridge over the river Huerva, modelled on those installed in other European cities in that century. It was conceived as a space for public amusement and conviviality, and offered a wide variety of shows and forms of entertainment that were fashionable at that moment: concerts, plays, zarzuelas, dances and walking areas. It was also an indispensable element in the construction process of urban modernity in this city. It disappeared at the end of the nineteenth century, although the land was used for other purposes until the Thirties when the Elysées building (paseo de Sagasta, nos. 2 and 4, corner of Gran Vía, nos. 1 and 3) was built.

KEYWORDS: Champs Elysées; Zaragoza; $19^{\text {th }}$ Century Urban Planning; Playground; Velodrome.

Recibido: 5 de enero de 2018 / Aceptado: 9 de mayo de 2018.

[...] Pero sí, soy mayor / y amo aun lo que apenas si recuerdo: la madrugada alta y su ginebra, / la nuca que termina en rizo último entre tus dientes [...].

Y a la mañana al sol, junto a la barca, / leer el mismo libro de mis días.

Introducción

«Edad», Los Campos Elíseos, Pablo García Baena

Este texto tiene como finalidad contribuir a trazar la historia de los Campos Elíseos de Zaragoza como espacio público para el entretenimiento y la sociabilidad cívicos. Este jardín de recreo fue emplazado en una zona que, en esos momentos, se hallaba en las afueras de la ciudad y fue inaugurado durante la celebración de las fiestas del Pilar del año 1868.

Este establecimiento se ubicó en el paseo o camino de Torrero (hoy paseo de Sagasta)', junto al puente del río Huerva (que actuaba como barrera natural que obstaculizaba el crecimiento hacia el Sur)², en unas parcelas de alto valor para

Cómo citar este artículo: VÁZQUEZ ASTORGA, Mónica, "Los Campos Elíseos de Zaragoza: un sitio de recreo urbano para la sociedad decimonónica», Boletín de Arte-UMA, n. ${ }^{\circ}$ 39, Departamento de Historia del Arte, Universidad de Málaga, 2018, pp. 255-270, ISSN: 0211-8483, DOI: http://dx.doi.org/10.24310/BoLArte.2018.v0i39.4862 
la construcción cuando la ciudad se desarrolló hacia esta parte, integrándose así en el contexto urbanístico. Por tanto, estaba cerca de la plaza de Aragón ${ }^{3}$, que debe ser concebida, como bien expresa Isabel Yeste (2016: 394), como punto de arranque del ensanche del siglo $X X^{4}$. De ahí que su instalación tuviera una importante función simbólica en el proceso de creación de modernidad urbana en Zaragoza y una notable trascendencia en este ámbito.

Los Campos Elíseos se extendían en el amplio solar ocupado actualmente por el denominado popularmente edificio Elíseos (levantado en la confluencia del paseo de Sagasta, núms. 2 y 4, con la Gran Vía, núms. 1 y 3), que fue proyectado por el arquitecto zaragozano Teodoro Ríos Balaguer en 1939 y terminado en 1945 (Aldama, 2006: 633 y 642).

La apertura de esta clase de lugares, como señala Jesús Cruz (2015: 37), formó parte de las agendas reformistas de los nuevos grupos dominantes que estaban interesados en llevar la modernidad a la urbe y a la sociedad en general. Además, las teorías higienistas de la época veían en los parques, los jardines y los paseos arbolados no sólo un medio de embellecer la ciudad, sino sobre todo una necesidad indispensable para proporcionar sosiego y bienestar a los habitantes, conforme a la influencia del urbanismo de Londres y París (Rodríguez y Prieto, 1997: 399 y 414).

Los primeros jardines de recreo aparecieron en Londres a finales del siglo XVII, pero se hicieron más frecuentes en la siguiente centuria, cuando los jardines de Vauxhall (en la orilla sur del Támesis) se convirtieron en el lugar de esparcimiento preferido para las clases acomodadas en las noches de verano. Los primeros en el continente se abrieron en París en la segunda mitad del siglo XVIII y se tipificaron en los jardines de Tívoli (inaugurados en 1766) ${ }^{5}$. A diferencia de los jardines ingleses que ofrecían una programación de entretenimiento de alta cultura (enfocada en la música, los bailes y el teatro), los franceses incluyeron formas populares de espectáculo ${ }^{6}$.

Después se fueron introduciendo nuevos tipos de jardines de recreo, entre ellos, los Campos Elíseos que incluían una variada oferta de atracciones, actuaciones musicales, obras de teatro y bailes.

Por tanto, el jardín de recreo fue la versión española en el siglo XIX del pleasure garden inglés y del parc de loisirs francés, todos ellos como sitios creados en la urbe moderna para la comercialización del ocio cívico (Cruz, 2015: 37)7.
Fue durante el período comprendido entre el reinado de Isabel II (1833-1868) y el de Alfonso XII (1874-1885) cuando surgieron los jardines dispuestos para el paseo, la práctica deportiva y la exhibición de espectáculos y de animales (Sánchez, 2009: 143). Su desarrollo se vincula a la revolución liberal y, por tanto, al acceso de la burguesía a los ámbitos de decisión política, permitiendo una nueva definición de los espacios públicos y sus funciones (Uría, 2001: 254).

La fundación de jardines, parques y paseos llegó a ser un elemento característico de las reformas urbanas del siglo XIX. De este modo, muchas capitales, entre ellas Zaragoza, abrieron durante esta centuria jardines con el nombre de Campos Elíseos, continuando con el modelo francés y con elementos propios de los ingleses. El primero de ellos se ideó en Barcelona en 1853, dado que esta ciudad siempre había destacado en materia de espectáculos y diversiones públicos. A este se sumaron, como veremos a continuación, el de Madrid y el de Zaragoza, a los que les siguieron los de Lérida y Gijón, entre otros.

En estos establecimientos, y rindiendo homenaje a su denominación, se proporcionaba distracción, comodidad y honestos placeres. Así, la expresión Campos Elíseos procede etimológicamente del griego ${ }^{8}$. Algunos autores clásicos tardíos se refirieron a esta en plural, ya que tradicionalmente se empleó en singular, Elýsion pedion (en plural, Elýsia pedía) ${ }^{9}$. Igualmente, suele traducirse en singular, respetando el griego antiguo («la llanura del Elíseo», «Campo Elíseo»), o en plural, término al que estamos más acostumbrados ("Campos Elíseos»). Según la mitología clásica, era un lugar paradisiaco donde las almas de los muertos (que en vida habían sido virtuosos y justos) pasaban plácidamente una eternidad dichosa y feliz ${ }^{10}$. Se oponía al Hades, al inframundo, siendo el Tártaro (donde los condenados sufrían eternos tormentos) la parte más profunda del mundo que, con el tiempo, acabó por hacer referencia al mencionado inframundo (Grimal, 1981: 220-221 y 493-494).

Para abordar este tema de estudio, aludimos, en primer lugar, a los dos primeros jardines fundados como Campos Elíseos en nuestro país, dado que sirvieron de referente para los que se instalaron con posterioridad en otras ciudades de nuestra geografía; en segundo lugar, nos centramos en el erigido en Zaragoza en 1868, analizando sus características y devenir histórico; y, por último, señalamos los va- 
rios destinos que tuvo su terreno después de la desaparición del último vestigio de este espacio de recreo en 1892.

\section{Los primeros Campos Elíseos: Barcelona y Madrid}

El primer establecimiento de esta clase fue creado en Barcelona e inaugurado el 10 de abril de 1853 (El Áncora' 9 de abril de 1853: 160, y El Áncora, 11 de abril de 1853: 178-179). En aquel momento era el mayor jardín de recreo construido en nuestro país y podía competir dignamente con los más renombrados de la época.

Ocupaba una amplia extensión de terreno y estaba situado en el lado derecho del passeig de Gràcia (eje axial del Eixample), por tanto, en una de sus principales vías urbanas ${ }^{11}$. Tenía aproximadamente, como precisa Jesús Cruz (2015: 47), el mismo tamaño que los jardines de Cremorne de Londres y su estructura, propósito y tipos de entretenimiento eran similares a los del Tívoli de Copenhague.

Todas sus instalaciones, así como su teatro, fueron diseñados por el arquitecto barcelonés Josep Oriol Mestres (Villoro, 1984: 41). Un conjunto de amplias avenidas conducía al núcleo central del parque conformado por una gran plaza circular programada para variados espectáculos y la instalación de un teatro.

Siguiendo la idiosincrasia del parc de loisirs francés proporcionaba funciones de circo, espectáculos de efectos visuales, una vasta variedad de atracciones mecánicas (montaña rusa -que sería la primera en funcionamiento en nuestro país, en 1853-, columpios, etc.), así como puestos de feria para solaz de la distinguida sociedad barcelonesa. Al mismo tiempo imitaba la tradición inglesa al presentar un repertorio cuidadosamente programado de ópera y música clásica (Cruz, 2015: 47).

Comprendía lujosos locales para restaurant y café, e, incluso, una modesta vaquería suiza en donde eran ordeñadas las cabras y vacas en presencia de todo el que gustase degustar su exquisita leche (El Áncora, 11 de marzo de 1853: 1.128). Los precios de la entrada, como para las funciones y juegos (2 rs. al recinto y 8 rs. a los conciertos), eran menores que los exigidos en París, Londres u otras capitales europeas, habiéndose implementado un sistema de abonos con el fin de reducir su coste y facilitar la concurrencia diaria. A pesar de estas medidas, su desaparición tuvo lugar en
1873 debido a la disminución de su éxito y al aumento de la edificación en el passeig de Gràcia que, con el proyecto del Eixample, se había revalorizado.

Pocos años después, se instalaron los Campos Elíseos de Madrid (en un terreno sito fuera de la Puerta de Alcalá) (Répide, 2002: 125). La propuesta para el desarrollo de esta posesión para el recreo público se formuló a comienzos de 1858 (Diario oficial de avisos de Madrid, 1858: 4). Su planificación, promovida por el empresario catalán José Casadesús y suscrita por el arquitecto Lucas M. ${ }^{a}$ Palacio el 29 de septiembre de 1860, ocupaba una extensa superficie, con árboles y plantas, que estaba limitada por una tapia en la que se abrieron una serie de puertas para el acceso, encontrándose la principal en la carretera de Aragón (hoy calle de Alcalá) ${ }^{12}$. Su apertura estaba prevista para el 15 de junio de 1864 (Diario oficial de avisos de Madrid, 22 de mayo de 1864: 4), pero no se efectuó hasta el sábado 18 de ese mes "por causas ajenas a la voluntad de la empresa» ${ }^{13}$. Tenía un uso estacional, dado que se inauguraba cada temporada en primavera y se cerraba en otoño.

Este frondoso vergel se encontraba integrado por distintos espacios (como por una gran plaza, circular, destinada a funciones de fuegos artificiales, ejercicios gimnásticos y de equilibrio y otros espectáculos parecidos) y, de entre todos los edificios que lo componían, destacaban el salón de conciertos (alzado en «forma de tienda de campaña» y vistosamente decorado, donde se ofrecían conciertos vocales e instrumentales), el teatro (dedicado al compositor Rossini y ubicado en el centro de los jardines, donde actuaron renombradas compañías de ópera y de baile) $)^{14}$, la casa de baños ${ }^{15}$, la fonda-restaurant y el café.

También, los visitantes podían disfrutar de formas de entretenimiento tan variadas como las siguientes: paseando por los jardines (bañados por las aguas del Canal de Isabel II), subiendo a una embarcación que navegaba por la ría (que estaba en el ala oeste del parque) [1] (El Museo Universal, 1864: 205), montando en una montaña rusa o en columpios, asistiendo al velódromo o a un espectáculo taurino en la plaza (denominada en la prensa de la época «plaza de becerros o de toretes» para diferenciarla del coso principal de la ciudad), jugando al billar o practicando el tiro de pistola. La entrada a los jardines se fijó, desde las primeras horas de la mañana hasta las cinco de la tarde, en 2 reales, y desde esta hora en adelante en 4, y, en caso de concurrir al teatro, había 


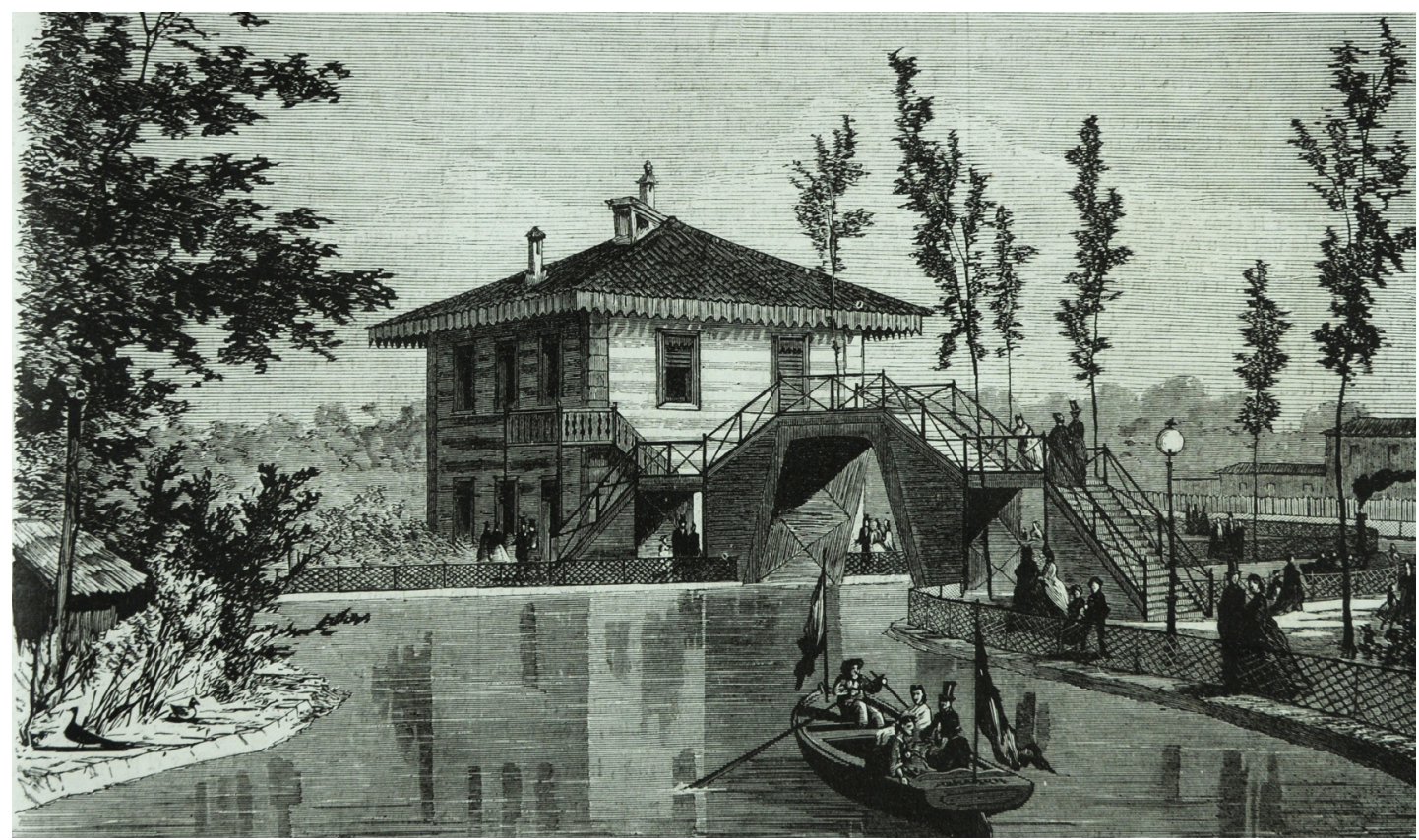

1. Vista de la ría de los Campos Elíseos de Madrid (El Museo Universal, Madrid, 26 de junio de 1864) (Biblioteca de la Diputación Provincial de Zaragoza)

que pagar una cantidad adicional (Diario oficial de avisos de Madrid, 7 de junio de 1864: 4).

Estos Campos Elíseos se convirtieron en el centro de recreo veraniego predilecto de la sociedad madrileña en época isabelina. No obstante, tuvieron una efímera existencia porque en la década de los setenta comenzó su destrucción al ir configurándose las primeras manzanas del nuevo barrio de Salamanca. De hecho, su empresa arrendataria anunció en la prensa, el 29 de septiembre de 1875, su cierre al no resultar económicamente rentable (Diario oficial de avisos de Madrid, 29 de septiembre de 1875: 4), y cuatro meses después se subastó el derribo de algunas de sus construcciones (Diario oficial de avisos de Madrid, 19 de enero de 1876: 3) ${ }^{16}$, permaneciendo únicamente en funcionamiento su «plaza de toretes», casa de baños y jardines (para bailes campestres). Lo último en desaparecer fue su modesto coso taurino en $1881^{17}$.

Los Campos Elíseos de Barcelona y Madrid, al igual que algunos de sus homólogos europeos, fueron el escenario para la sociabilidad de buen tono y desempeñaron un papel decisivo en la conformación de la esfera pública de época liberal (Cruz, 2015: 51). Sin embargo, los Campos Elíseos de Zaragoza se inauguraron, como veremos a con- tinuación, poco después de la Revolución de 1868, coincidiendo con un momento de cambio profundo. La «Gloriosa» abrió los horizontes de las primeras formas democráticas en la política, en la cultura y en el control social de la ciudad (Forcadell, 1997: 47), que se cerraron seis años después con el período de la Restauración borbónica.

\section{Los Campos Elíseos de Zaragoza: un oasis de recreo a orillas del Huerva}

Al final del período isabelino, Zaragoza se había reforzado como capital política, económica y administrativa. De ahí que, al igual que otras ciudades, se sumase a esta iniciativa de modernización urbana con la instalación de un espacio abierto y arbolado para el esparcimiento de la población.

Fue inaugurado oficialmente el 11 de octubre de 1868 (El Diario de Zaragoza, 8 y 11 de octubre de 1868: 3), prácticamente un mes después de la Revolución de 1868, que fue, como recoge María Victoria López-Cordón (1976: 1), una brusca sacudida en la historia de nuestro siglo XIX. Por tanto, fue testigo del cambio político que se vivió en 


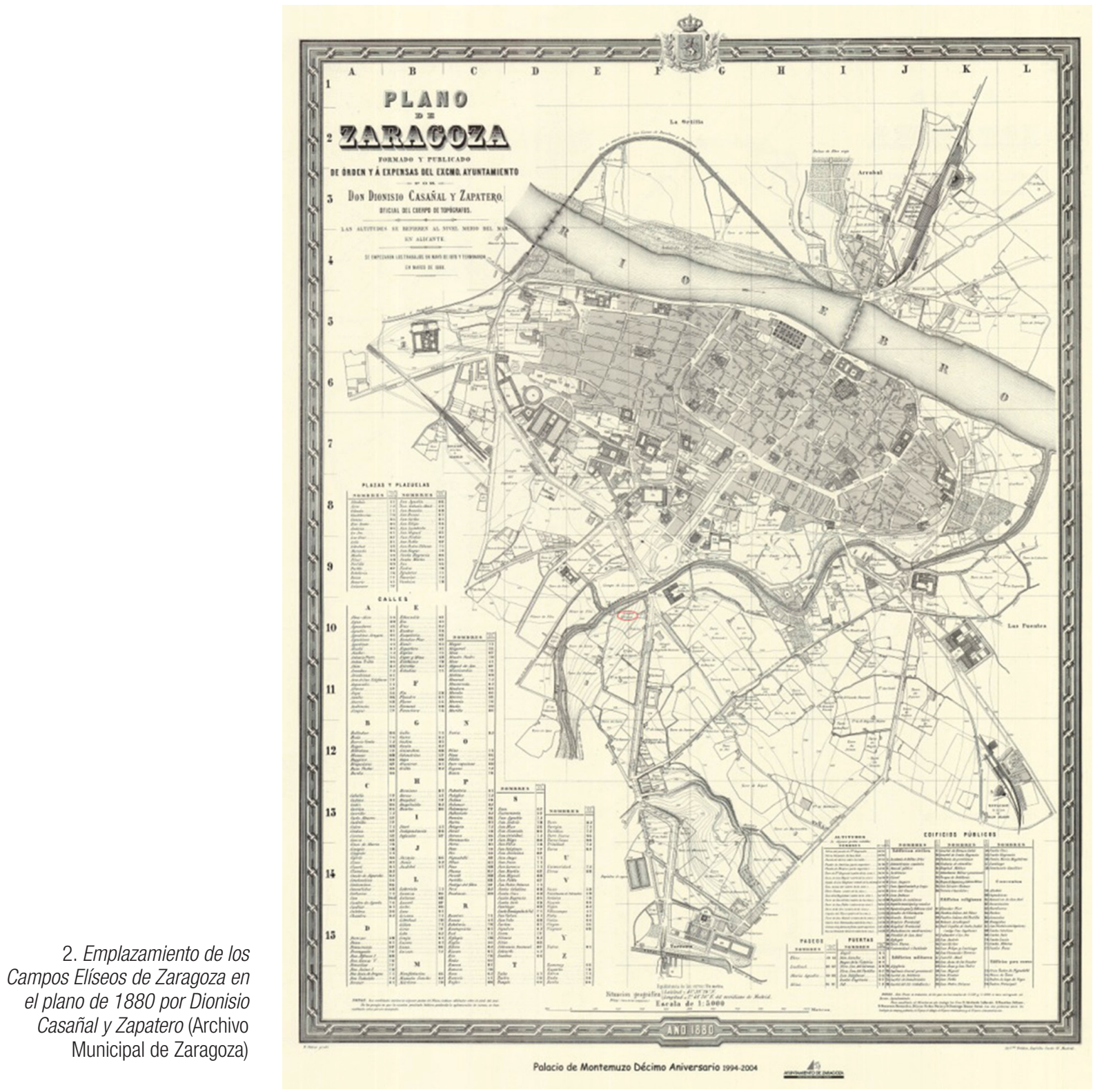

Zaragoza. Así, hasta ese momento, y como indica Carlos Forcadell (1997: 61-62), la ciudad burguesa convivía con una ciudad popular que protagonizaría las jornadas revolucionarias que acabaron temporalmente con la monarquía borbónica. De hecho, a principios del mes de octubre una junta revolucionaria tomó el poder, que se disolvió cuando el gobierno provisional convocó elecciones por sufragio universal para conformar las Cortes constituyentes que elaboraron la Constitución democrática de $1869^{18}$.
Este recinto era similar en estructura, contenidos y localización a los de Barcelona y Madrid. Era un extenso complejo de propiedad privada emplazado en el inicio del paseo o camino de Torrero (actual paseo de Sagasta), junto al puente del Huerva (cuyo cauce estaba descubierto en esos momentos), por lo que este sector disfrutaba de una abundante provisión de agua procedente de este río [2] ${ }^{19}$. Esta vía estaba situada fuera del perímetro urbano señalado por el muro que cerraba la ciudad. En concreto, se asentó 


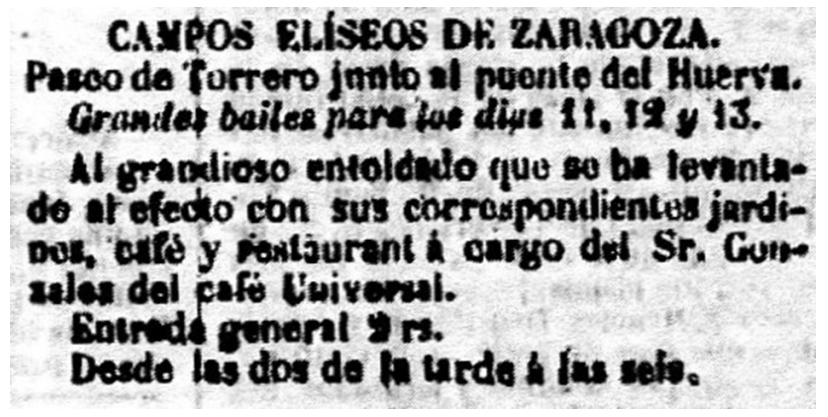

3. Anuncio de los Campos Elíseos de Zaragoza (El Diario de Zaragoza, Zaragoza, 11 de octubre de 1868, p. 3) (Archivo Municipal de Zaragoza)

en un terreno rural donde anteriormente había existido un olivar, contiguo a la alfarería de Benito Parellada ${ }^{20}$.

Por tanto, ocupaba una posición estratégica y, aunque todavía no existía el paseo de Sagasta, se integraba perfectamente en el contexto urbanístico, actuando como elemento de unión entre el nuevo centro urbano organizado en torno a la plaza de Aragón (a la que convergerían grandes bulevares radiales como los futuros paseos de Pamplona o de la Gran Vía) y la nueva vía de comunicación (paseo de Sagasta) clave en la organización de la ciudad.

En esta zona ubicada al Sur, tras la Puerta de Santa Engracia, se localizaban a finales del siglo XIX, como constata Ascensión Hernández (1991-1992: 435-436), las nuevas industrias, la nueva Facultad de Medicina y Ciencias (1887), obra del arquitecto municipal Ricardo Magdalena Tabuenca, así como el actual paseo de Sagasta. De este modo, a sus lados se encontraban por estas fechas numerosas to- rres $^{21}$, algunas industrias (como la alfarería de N. Gracia) y otras propiedades como el colegio del Sagrado Corazón o la Huerta de los PP. Jesuitas quienes tenían su colegio ${ }^{22}$ muy próximo al puente del Huerva.

Antes de la existencia de este recinto, el número de zonas ajardinadas para el paseo, el esparcimiento y la sociabilidad cívica era limitado. Los únicos alicientes en esos momentos para caminar al aire libre (y en la otra parte de la ciudad) eran el paseo del Ebro, la Arboleda de Macanaz -donde se organizaban bailes y verbenas-, las Balsas del Ebro Viejo y la Torre de Bruil23, con sus pintorescos jardines (Blasco, 1955: 10). De ahí que los Campos Elíseos puedan considerarse como el primer sitio de recreo moderno en Zaragoza. La idea de su construcción surgió de los empresarios catalanes Sebastián y Agustín Viñals y fue acogida con entusiasmo por la sociedad zaragozana.

A pesar de que no hemos localizado hasta la fecha el proyecto de este lugar de recreo ${ }^{24}$, y dado que se trató de una iniciativa emprendida por gestores catalanes, consideramos que seguiría en esencia el modelo de los Elíseos establecidos en Barcelona. No obstante, tenemos constancia de que ocupaba un amplio espacio ajardinado en forma trapezoidal, en el que se dispusieron estructuras efímeras de madera y yeso para un teatro ${ }^{25}$, circo, salón de baile, casa de baños, restaurant y cafée ${ }^{26}$, así como garitas para el tiro de gallina (El Diario de Zaragoza, octubre de 1880: 1-2) o el tiro de paloma (El Diario de Zaragoza, diciembre de 1880: 2). Estaba delimitado por una tapia con el objetivo de controlar el acceso durante las actuaciones.

En él se ofrecía entretenimiento previo pago de una entrada, siendo así exclusivo para la buena sociedad. El pre-

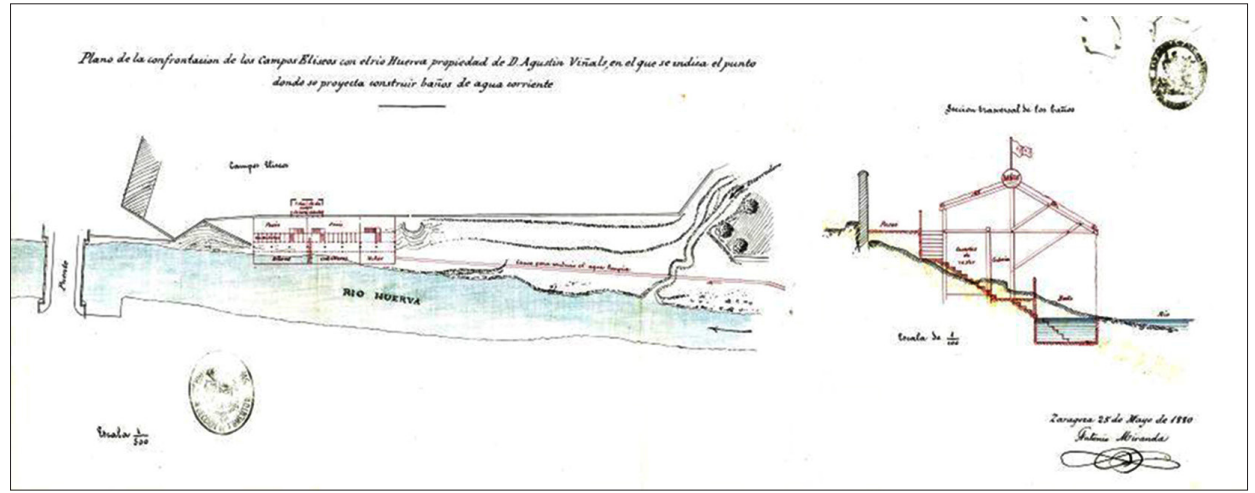

4. Plano de la confrontación de los Campos Elíseos con el río Huerva con indicación de donde se proyectan construir baños de agua corriente y sección transversal de los mismos, por Antonio Miranda, 25 de mayo de 1880 (Archivo Municipal de Zaragoza) 
cio de la entrada general era de 2 rs. y si se deseaba tener silla de preferencia en los espectáculos de 4 reales [3] (El Diario de Zaragoza, 11 de octubre de 1868: 3). Tenía carácter estacional, abriendo sus puertas a mediados de primavera y cerrándolas a mediados de otoño (después de las fiestas del Pilar).

En concreto, el circo fue uno de los últimos edificios en instalarse, siendo inaugurado el 25 de febrero de 1879 (E) Diario de Zaragoza, 24 de febrero de 1879: 2). Poco tiempo después, Sebastián Viñals, en calidad de arrendatario de los Campos Elíseos, solicitó permiso al Ayuntamiento, con fecha de 24 de mayo de 1880, para poder establecer una casa de baños de agua corriente en la margen del río Huerva lindante con dicha posesión. Su construcción, proyectada por Antonio Miranda ${ }^{27}$, debía responder a las siguientes circunstancias: no perjudicaría a ningún inmueble o terreno de los inmediatos y se ubicaría dentro de la propiedad dando entrada a la misma por la puerta principal situada en el paseo de Torrero [4] ${ }^{28}$. Esta sencilla estructura, levantada en madera (y como las demás con carácter efímero), se adaptaba al terreno y daba paso a través de una galería a tres zonas, perfectamente separadas: una reservada para los hombres, otra para las mujeres y una tercera para los niños, y cada una de ellas con sus respectivas salas de vestir.

El arquitecto municipal Ricardo Magdalena encontró conforme el diseño y la Sección de Fomento acordó el 20 de julio de ese año autorizar su obra con estas condiciones: 1 . $^{\text {a }}$ que tuviera naturaleza provisional y no alterase el curso de las aguas del río ni dañase el terreno; 2. a que cumpliera las ordenanzas municipales y el reglamento respecto a las condiciones higiénicas de moralidad; y 3. ${ }^{a}$ que se procediese a una inspección regular de las instalaciones por el Ingeniero Jefe de Obras Públicas. De este modo, se procedió a la apertura de los baños, durante la temporada de verano, que tuvieron una gran acogida por parte de la población (El Diario de Zaragoza, 10 de julio de 1883: 2).

Como hemos mencionado anteriormente, la entrada incluía los diferentes números programados en horario de dos a diez: conciertos de música clásica, bailes de sociedad, obras de teatro y de zarzuela (El Diario de Zaragoza, 12 de agosto de 1876: 3) y funciones de ejercicios gimnásticos (como las dirigidas por la renombrada familia Bourgois durante las fiestas del Pilar de 1876) [5] (El Diario de Zaragoza, 7 de octubre de 1876: 3) ${ }^{29}$, entre otros.

\section{Campoe Fliseos.}

Gran funcinn para mañana dominga, si el tirn. po no lo imuide por la cumpañ́f ecuestre y acrubática bajo la direccion de Mr. Bourgoia y compania. compuesta de primeros artistas que han llamado la atencion en aus diflciles y arriengados fiereicins durante este verno en ed Prado Catalan de Barcelona.

$A$ las tres de la carde. - Botrade general $2 \mathrm{~ns}$. -Sillas $4 \mathrm{rs}$.

Por is noche d las siete (y si el tiempo lo permite) se ejecutard una grande y veriada funcuon ecuestre y gumudstica a los previos expresados anteriormente.

5. Anuncio de los Campos Elíseos de Zaragoza (El Diario de Zaragoza, Zaragoza, 7 de octubre de 1876, p. 3) (Archivo Municipal de Zaragoza)

También cabe señalar que, en ocasiones, se cedieron algunos de sus espacios para reuniones de contenido cívico y político, cuya finalidad era promover nuevas corrientes ideológicas. Así, dos días después de que en el teatro Rossini de los Campos Elíseos de Madrid se celebrara el 22 de octubre de 1871 (cinco meses después de los sucesos de la Comuna de París) un mitin de partidarios de la Asociación Internacional de Trabajadores ${ }^{30}$, se verificó un encuentro con el mismo fin en su teatro (El Diario de Zaragoza, 24 de octubre de 1871: 1).

Los Campos Elíseos tuvieron una efímera existencia como lugar de recreo a causa de la inestabilidad financiera de la empresa arrendataria y no llegaron a alcanzar los éxitos de sus homólogos. Aunque su cierre tuvo lugar en $1883^{31}$, los jardines y el circo (convertido en «plaza de toretes») mantuvieron ciertos rasgos de permanencia. De hecho, en los jardines se organizaban bailes públicos y el coso era rentado para la lidia de novillos y becerros (El Diario de Zaragoza, 10 de octubre de 1891: 2) y funciones ecuestres, siendo el último vestigio en desaparecer a finales del año 1892 (El Diario de Zaragoza, 4 de noviembre de 1892: 4).

No obstante, la apremiante necesidad de espacios salubres para el disfrute de los ciudadanos fue atendida con la instalación de otros lugares de parecida índole, encontrándose entre ellos la Quinta Julieta que se localizaba en la parte Sureste de la urbe, junto al Canal Imperial de Aragón, y cerca 


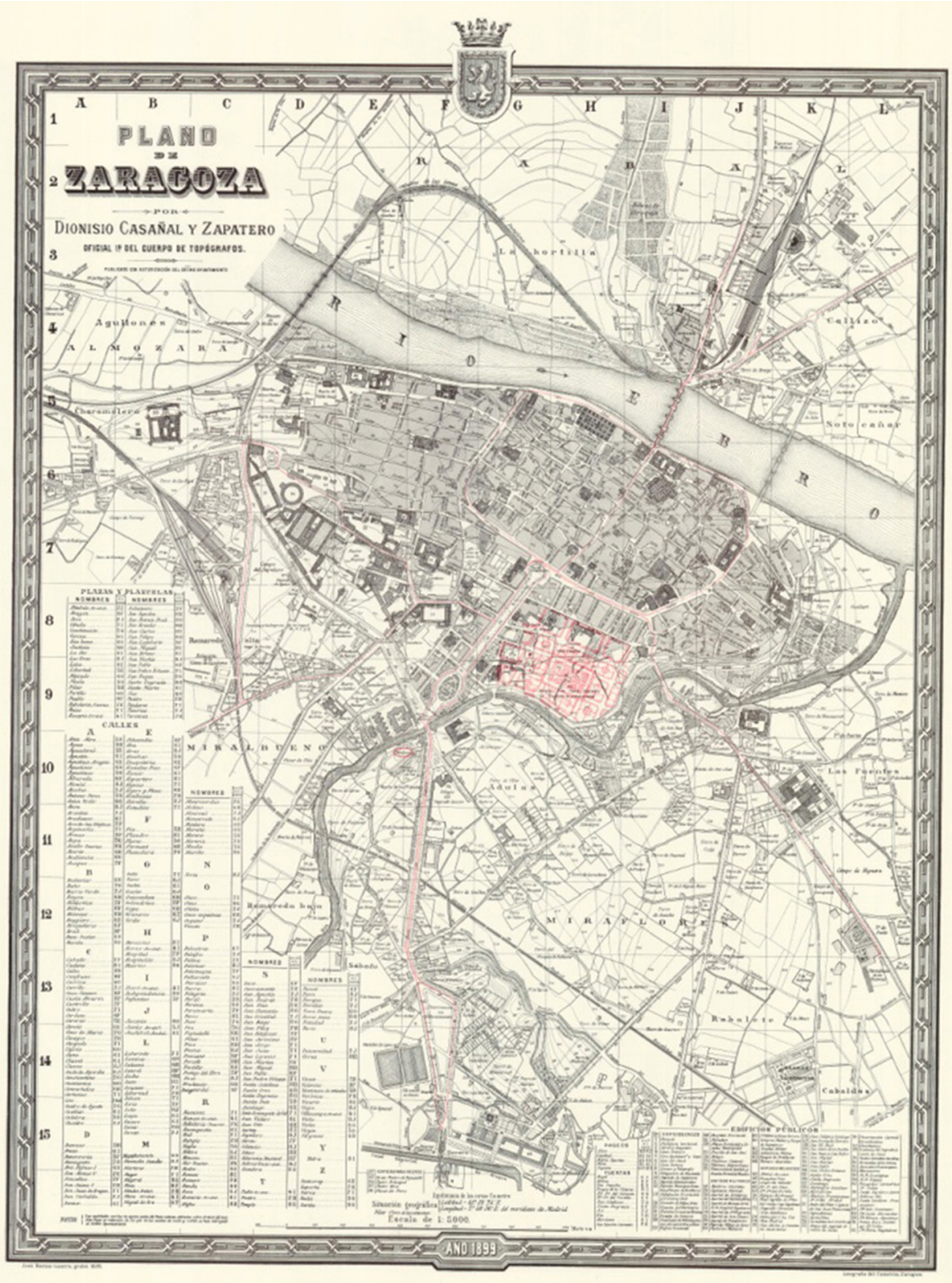

6. Emplazamiento del velódromo de los Campos Elíseos de Zaragoza en el plano de 1899 por Dionisio Casañal y Zapatero (Archivo Municipal de Zaragoza) del Cabezo Cortado ${ }^{32}$. Fue inaugurada el 30 de mayo de 1897 como finca de recreo privada y al mismo tiempo con acceso público (Diario de Zaragoza, 29 de mayo de 1897: 6). Por tanto, la alineación del paseo de Sagasta y su urbanización favorecería también la comunicación con este sitio de esparcimiento que contaba con alicientes naturales (grutas con cascada y estanques, rodeados por paseos arbolados), amenas atracciones (entre ellas, una placita de toros y tiro al pichón) y varias construcciones (Heraldo de Aragón, 2 de julio de 1915: 5). Con fecha de 27 de marzo de 1917 fue vendida por sus dueños, Enrique Sagols Ferrer y su esposa Julia Rodrigo Coutens, y adquirida por los PP. Jesuitas (ACS Zaragoza, 1917), siendo destinada posteriormente a otros fines ${ }^{33}$.

Otro grato lugar existente en Zaragoza en la segunda mitad del siglo XIX fue la Torre de Bruil, una amplia finca dedicada a parque y jardines (con singulares plantas y flores), 
que tomaba el nombre de su propietario Juan Faustino Bruil (Blasco, 1955: 11).

Sin embargo, estas iniciativas pronto tuvieron el mismo destino que los Campos Elíseos.

\section{La posesión de los Campos Elíseos tras la desaparición del jardín de recreo}

Pocos años después de la desaparición del lugar de recreo, el terreno de los Campos Elíseos se destinó a velódromo con igual denominación [6] $]^{34}$, patrocinado por la Sociedad Velocipédica Zaragozana ${ }^{35}$. De este modo, se deseaba responder a la afición a las carreras de velocípedo que se había extendido a partir de la década de los ochenta, por considerarse un «ejercicio higiénico recomendado por la ciencia» (El Imparcial, 7 de noviembre de 1882: 2).

Antonio Bovio (contratista de origen italiano) solicitó licencia al Ayuntamiento de Zaragoza, el 20 de marzo de 1896, para que como propietario (junto con su hermano Luis) del velódromo que estaba en construcción pudiera modificar los huecos y la decoración de la puerta principal de su fachada al paseo de Sagasta y chaflán, conforme al plano formulado por Antonio Miranda [7] y [9] ${ }^{36}$. Para ello, contaba con el visto bueno de su dueño, Mariano Royo, y se le concedió autorización el 14 de abril de ese año (AMZ Zaragoza, expediente n. $\left.{ }^{\circ} 532,1896\right)$. La portada presentaba un ingreso en arco de medio punto, flanqueado por dos pilastras de orden corintio, sobre el que se dispuso un remate ornamentado en su centro con la representación, en relieve, de una bicicleta.

Este nuevo velódromo, construido por el ingeniero Luis Montesino, fue inaugurado el 3 de mayo de 1896 (La Época, 1896: 3), con seis carreras (entre locales, regionales e internacionales, en las que tomaron parte acreditados campeones) (Borbón, 1896: 15), asignándose el producto íntegro de la entrada a beneficio de los soldados aragoneses heridos en la campaña de Cuba (El Liberal, 12 de abril de 1896: 3, y El Liberal, 19 de abril de 1896: 2-3). La inauguración fue un importante acontecimiento social y se llenaron todas las localidades (El Deporte Velocipédico, 1896: 2-3).

Tenía capacidad para 3.000 espectadores sentados y en los edificios colindantes existía un espacio reservado para la Sociedad Velocipédica Zaragozana, así como una sala para estos vehículos [10] (Heraldo de Aragón, 1896:

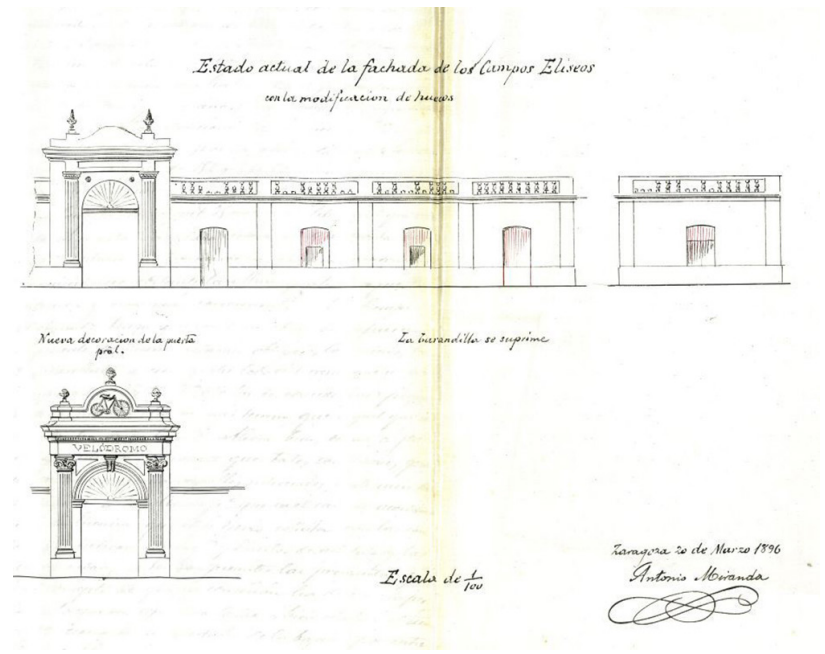

7. Estado actual de la fachada de los Campos Elíseos con la modificación de huecos y la nueva decoración de la puerta principal, por Antonio Miranda, 20 de marzo de 1896 (Archivo Municipal de Zaragoza)

2). En otro inmueble estaba el salón de venta y alquiler de máquinas y patines, los servicios higiénicos y unas oficinas. Asimismo, junto a la entrada, había un restaurant servido por el Lion d'Or, que estaba al servicio de los ciclistas y del público ${ }^{37}$. Posteriormente, se colocaron focos de luz eléctrica entre los árboles que sombreaban la entrada y en la pista para celebrar las fiestas nocturnas. En la prensa periódica de la época se publicitaba como «el pulmón de Zaragoza en las noches de verano», pues su orientación le hacía recibir el viento fresco del Moncayo y el relente del Huerva (Heraldo de Aragón, 4 de mayo de 1896: 2).

En 1923 se reformaron las instalaciones del velódromo y su espacio, como señala Amparo Martínez (1997: 123 y 231), fue habilitado en aquellos años, y sobre todo durante los meses estivales, para la realización de bailes, conciertos y sesiones de cine al aire libre, como la velada que se anunció el domingo 23 de mayo de 1923 por la tarde y a la que se podía asistir pagando una entrada de 25 céntimos $^{38}$.

Por tanto, la posesión de los Campos Elíseos y sus dependencias fueron utilizadas para numerosos fines relacionados con el entretenimiento y, especialmente, para la

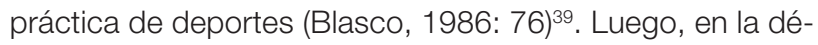
cada de los treinta, fue campo de fútbol hasta que los propietarios parcelaron estos terrenos para vender los solares resultantes (Ruiz, 1998: 146). Después de la contienda civil, 


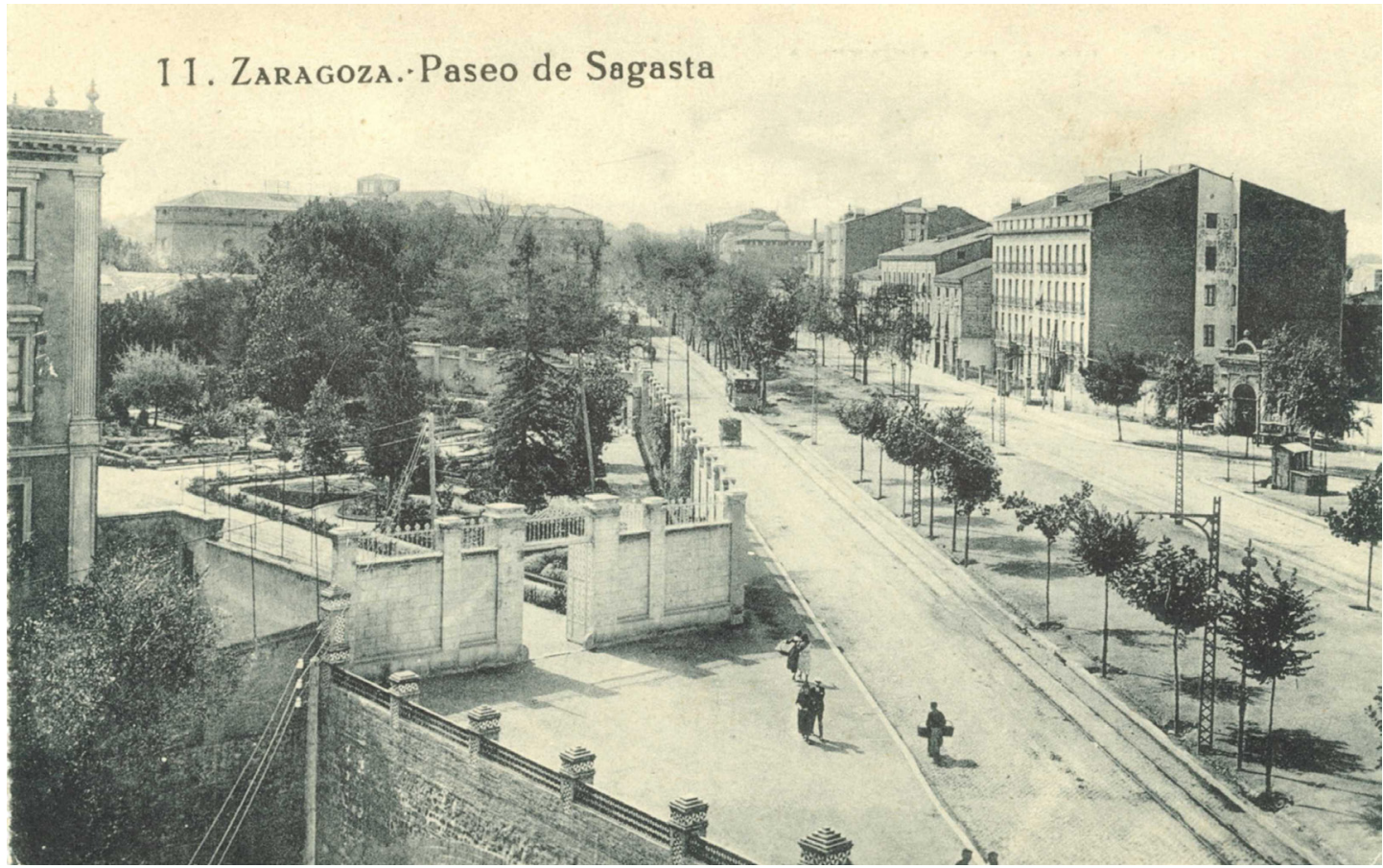

8. Vista del paseo de Sagasta de Zaragoza (a nuestra izquierda se aprecia el Colegio del Salvador y a nuestra derecha la puerta principal del velódromo), hacia 1920-1925 (Colección Luis Serrano Pardo, Zaragoza)

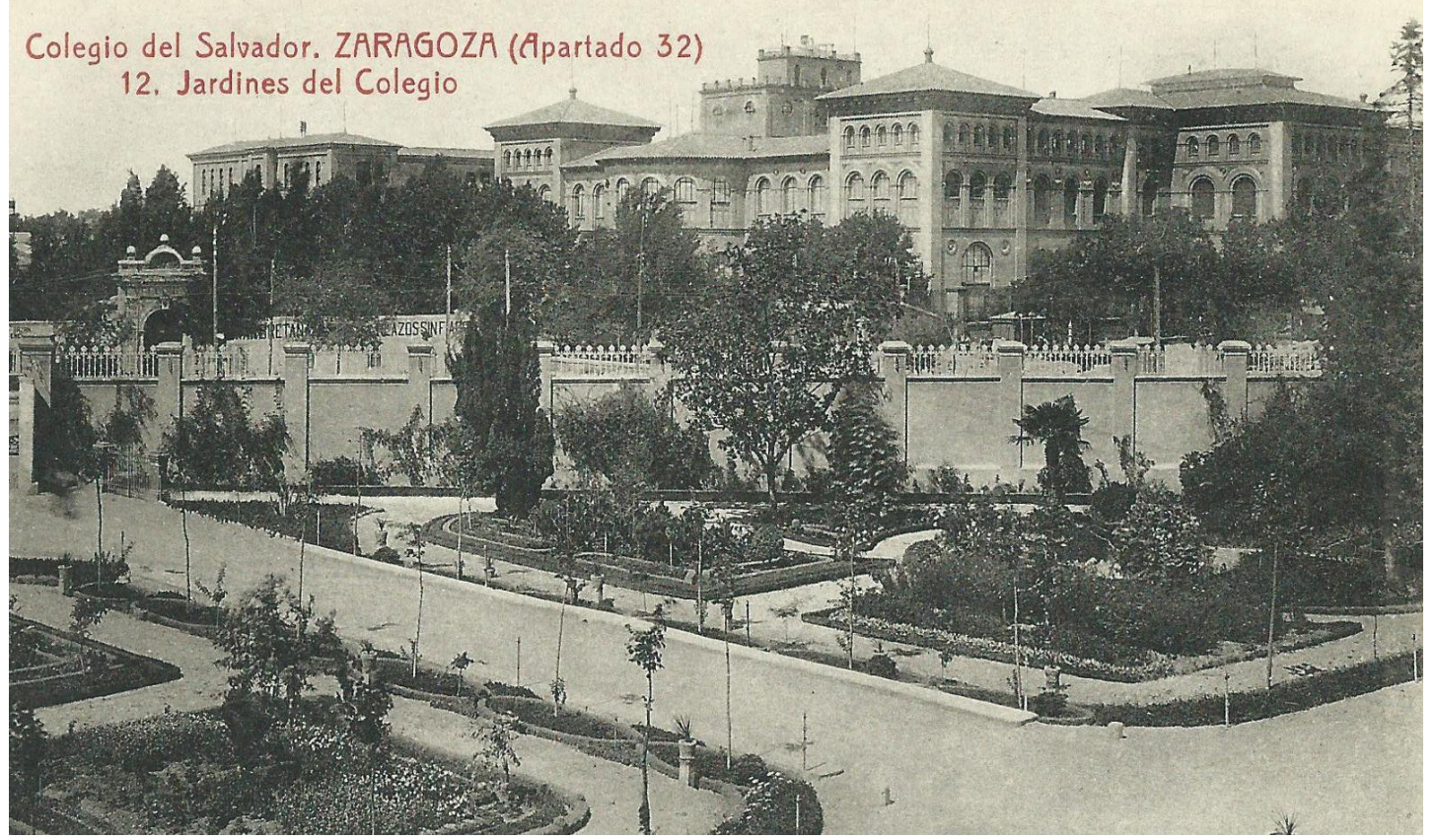

9. Vista tomada desde los jardines del Colegio del Salvador -paseo de Sagasta, núm. 1- (a nuestra izquierda se observa la puerta principal del velódromo y a la derecha el edificio de la antigua Facultad de Medicina y Ciencias), hacia 1900-1918 (Archivo del Colegio del Salvador, Zaragoza) 
10. Vista parcial del velódromo de los Campos Elíseos de Zaragoza el día de su inauguración (Heraldo de Aragón, Zaragoza, 4 de mayo de 1896, p. 2) (Archivo Municipal de Zaragoza)

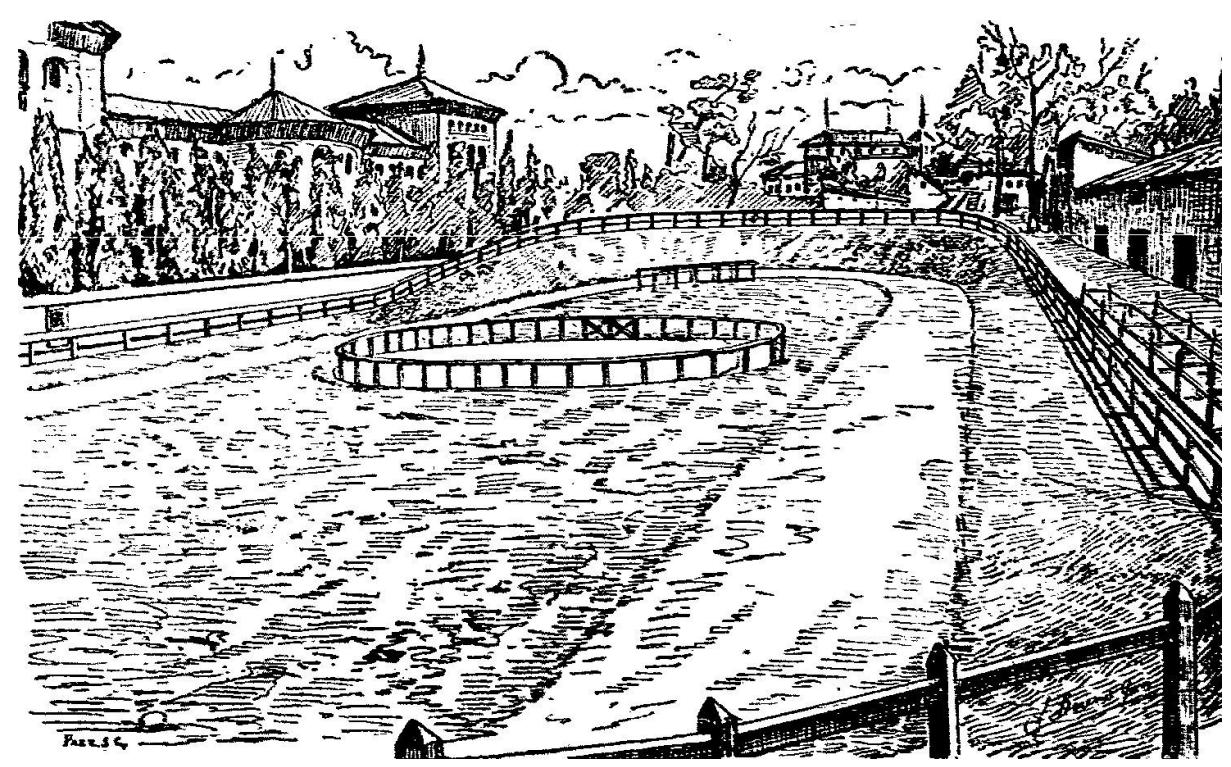

el recinto deportivo fue derribado, levantándose en su lugar un edificio de viviendas de grandes dimensiones que fue proyectado en 1939 por el arquitecto Teodoro Ríos Balaguer, y que alberga en su interior un pequeño cine (cinema Elíseos -cuya apertura tuvo lugar el 22 de diciembre de 1944-, en la actualidad cerrado) determinado a conservar en su nombre la memoria de las antiguas instalaciones que habían ocupado ese solar.

En cierto modo, y como a continuación mencionaremos, el desarrollo del ensanche conllevó el final de los Campos Elíseos. De hecho, en Zaragoza, como en casi todas las ciudades europeas, los jardines de recreo no sobrevivieron, salvo alguna excepción, al crecimiento urbano del siglo XIX y principios de la siguiente centuria.

A comienzos del siglo XX, y como indica Ascensión Hernández (1991-1992: 435), Zaragoza se encontraba inmersa en un proceso de crecimiento económico y demográfico (de 60.000 habitantes en 1868 pasó a 110.000 en 1908) que se tradujo en la transformación de su forma urbana $^{40}$. Los límites tradicionales de la ciudad se mostraban insuficientes para acoger a la población y a la incipiente industria, y se produjo una tendencia natural de asentamiento extramuros -era todavía una urbe amurallada y cerrada por puertas- al Sur de la misma.

En 1902, y según proyecto del arquitecto municipal Ricardo Magdalena (aprobado en 1900), se inició la urbani- zación del paseo de Sagasta, uniendo así simbólicamente el nuevo centro urbano surgido en torno a la plaza de Aragón (que enlaza con el paseo de la Independencia y el casco antiguo) con el barrio periférico de Torrero ${ }^{41}$. La burguesía zaragozana escogió este paseo como residencia excepcional, impulsando su urbanización.

Estos espacios para la diversión y sociabilidad cívicas fueron decayendo paulatinamente con la llegada del siglo $X X$, el cual, a su vez, traería nuevas formas para el pasatiempo y ocio de la sociedad zaragozana ${ }^{42}$.

\section{Fin de recreo}

Los Campos Elíseos de Zaragoza fue un espacio de recreo público decimonónico que respondió a los ideales de urbanidad, sociabilidad, elegancia y confortabilidad burguesa, así como tuvo una especial relevancia en el proceso de construcción de la ciudad moderna. De ahí que se instalase próximo al nuevo centro urbano conformado en torno a la plaza de Aragón y en el punto de inicio del actual paseo de Sagasta como eje de expansión hacia Torrero.

Como hemos podido comprobar, su creación tuvo una notable trascendencia socioeconómica, cultural y simbólica que ha dejado su huella en la fisonomía urbana y en la identidad ciudadana. 


\section{Notas}

* Este trabajo se ha realizado en el marco del Grupo de Investigación de Referencia Vestigium (H19_17R), financiado por el Departamento de Innovación, Investigación y Universidad del Gobierno de Aragón y el programa operativo FEDER Aragón (2014-2020), y cuya investigadora principal es la Dra. Concepción Lomba Serrano; y del Proyecto Museos y distritos culturales: Arte e instituciones en zonas de renovación arquitectónico-urbanística, financiado por la Secretaría de Estado de I+D+i del Ministerio de Economía y Competitividad (código HAR2015-66288-C4-01-P) (MINECO/FEDER) y con el Dr. Jesús Pedro Lorente como investigador principal.

En este apartado quiero expresar mi más sincero agradecimiento al personal de la Biblioteca de la Diputación Provincial de Zaragoza (en especial, a Álvaro Lafuente Opla) y del Archivo Municipal de Zaragoza por el apoyo mostrado en la consecución de este trabajo.

1 El paseo de Sagasta seguía en su trazado el antiguo camino de Torrero, abierto a finales del siglo XVIII con motivo de la inauguración del Canal Imperial, que unía la ciudad con los depósitos de agua y el cementerio, en el alto de Torrero, que dio nombre al mismo. Al Camino se accedía por un puente sobre el río Huerva, accidente geográfico que lo separaba del resto de la urbe (Hernández, 1991-1992: 435-436).

2 El puente sobre el Huerva desapareció cuando se desarrolló el proyecto del ensanche de esta zona en 1916 para iniciar su cubrimiento, que permitió acometer de manera definitiva la expansión de la ciudad hacia el Sur. Las obras se inauguraron el 30 de junio de 1924 (Heraldo de Aragón, 4 de abril de 1916: 1) y (Heraldo de Aragón, 1 de julio de 1924: 1).

3 Tras la clausura de la Exposición Aragonesa de 1868 (celebrada en la denominada Glorieta de Pignatelli -actual plaza de Aragón-), se planteó la urbanización de esta glorieta y su incorporación al perímetro de la ciudad. Para ello, el arquitecto municipal Segundo Díaz redactó un proyecto de parcelación de esos terrenos en abril de 1874.

4 Este plan de ensanche, a diferencia de otras ciudades, tuvo que esperar hasta principios del siglo XX, dado que hasta esa fecha la ciudad se había transformado hacia su interior. El desarrollo urbano se vio constreñido por limitaciones presupuestarias y por los intereses políticos de quienes controlaban el uso del suelo. Este plan consistió fundamentalmente en reafirmar la voluntad de crecimiento hacia el Sur, colmatando el espacio libre entre el viejo centro y los barrios periféricos, a partir de la plaza de Aragón (Forcadell, 1997: 59 y 72).

5 Muchas ciudades europeas, entre ellas Madrid y Florencia, crearon jardines con el nombre de Tívoli siguiendo el referente francés. El único superviviente de aquella generación de Tívolis es el de Copenhague, fundado en 1843. Para el estudio del Tívoli de Florencia, véase (Vázquez, 2018).

6 Los jardines ingleses y los franceses fueron los modelos exportados a otros lugares de Europa y América durante el siglo XIX. Para la historia de los jardines en América, véase (Conlin, 2013).

7 Los jardines de recreo de los siglos XVIII y XIX fueron el antecedente del parque de atracciones moderno.

8 En este punto, quiero expresar mi agradecimiento a la profesora Ana Cristina Vicente Sánchez (Área de Filología Griega, Departamento de Ciencias de la Antigüedad de la Universidad de Zaragoza) por las orientaciones proporcionadas a este respecto.

9 Según el diccionario etimológico de Pierre Chantraine (1999: 411) se barajan dos posibles etimologías. Una considera el término elýsion prehelénico, por lo que se desconocería su significado; la segunda lo hace derivar de otro término, enelýsios (que significa "alcanzado por un rayo»), el cual, al interpretarse erróneamente (por considerar que se trataría de la suma de la preposición de lugar y el topónimo «en el Elíseo») daría lugar al sentido "aquel que se encuentra en el Elíseo", de donde procedería la creación secundaria del término elýsion para designar la morada de los Bienaventurados. Esta etimología es un resumen de la propuesta por Walter Burkert (1960: 208-213).

10 Así, por ejemplo, puede leerse en Homero, Odisea 4.561-569, o en Luciano, Sobre el luto 7.

11 Se encontraba emplazado en una zona limitada por las actuales calles d’Aragó, Roselló y Roger de Llúria.

12 Este proyecto fue aprobado mediante Real Orden de 26 de enero de 1861, y se extendía, aproximadamente, entre las actuales calles de Alcalá, Velázquez, Goya y Castelló (Ariza, 1988: 344-350).

13 Entre los motivos que se mencionaron en la prensa periódica madrileña para el retraso de la inauguración de este establecimiento se aludió al hecho de que no se habían terminado las obras, así como que el tenor Pietro Mongini no había llegado a tiempo para la función inaugural prevista para el 15 de junio (Diario oficial de avisos de Madrid, 13 de junio de 1864: 4) y (Diario oficial de avisos de Madrid, 18 de junio de 1864: 4).

14 La prensa madrileña de la época ofrece la siguiente descripción de este teatro: «Es grande y fresco, bien alumbrado, y el golpe de vista que presenta, sorprendente. Pero su forma rectangular es impropia y entre otros graves inconvenientes hace permanecer en pie a los espectadores de los anfiteatros altos de los costados que no están en la delantera. Sencillez en su decorado, los palcos cómodos y los antepechos muy bajos, para que se luzcan las señoras. Las butacas son anchas, pero el paso estrecho y el declive de la platea insuficiente para ver con comodidad. La orquesta es magnífica y numerosa. Tiene precios demasiado elevados" (Diario oficial de avisos de Madrid, 20 de junio de 1864: 4). En febrero de 1865 el escenario de este teatro fue ampliado (Diario oficial de avisos de Madrid, 16 de febrero de 1865: 4).

15 Estaba situada en un jardín, rodeada de espaciosos cuartos y con cincuenta pilas de mármol blanco. Tenía también un magnífico salón de descanso o gabinete de lectura. El precio de la entrada era de 6 reales (Diario oficial de avisos de Madrid, 7 de junio de 1864: 4).

16 En el mes de noviembre de 1878 se informó del derribo del teatro de Rossini, de la fonda y del café de este recinto (Diario oficial de avisos de Madrid, 5 de noviembre de 1878: 4).

17 En esta posesión de recreo existió una pequeña plaza de toros que subsistió hasta el año 1873, por lo que se decidió levantar una nueva (que fue inaugurada el 14 de junio de 1875) que desapareció en 1881 (Archivo de Villa, Madrid -AVM Madrid-: 1865), (Diario oficial de avisos de Madrid, 10 de mayo de 1873: 3) y (Diario oficial de avisos de Madrid, 6 de junio de 1875: 4).

18 Este historiador señala que en todas las elecciones del Sexenio Democrático, incluidas las de la Primera República (1873), fueron los republicanos federales los que obtuvieron la mayoría electoral en Zaragoza (1997: 62).

19 Archivo Municipal, Zaragoza (AMZ Zaragoza), referencia de esta figura: 4-2_0072_0002.

20 Esta fábrica fue instalada por Parellada en el terreno de un olivar existente a la derecha del paseo de Torrero junto al puente del río Huerva. La finca era propiedad de Jacinto Corralé. La licencia para su construcción fue concedida el 17 de febrero de 1865. Tuvo una efímera existencia (AMZ Zaragoza, 1882).

21 En Aragón son casas de campo o recreo con granja o huerta. Entre esas torres se encontraba la de Miguel Hipólito de Val, que se hallaba contigua a los Campos Elíseos y a la huerta de los PP. Jesuitas (destinada al cultivo y ubicada en el número 12 del paseo de Sagasta) (AMZ Zaragoza, 1882). 
22 Este centro (paseo de Sagasta, n. ${ }^{\circ}$ ) dedicado a la educación religiosa y científica de la juventud se inauguró el 2 de julio de 1879 , frente a los Campos Elíseos. En su solar se levanta actualmente el edificio de la sede central de la entidad bancaria iberCaja (Heraldo de Aragón, 24 de noviembre de 1904: 1).

23 Los propietarios de esta finca (adquirida en los años cuarenta del siglo XIX y situada en la actual calle del Asalto, frente al trozo que media entre las calles de Cantín y Gamboa y Alonso V), Faustino Bruil y su esposa Ángela Mur Mendoza, procedieron a su venta el 23 de agosto de 1868 . A partir de esta fecha tomó otras derivaciones (Blasco, 1955: 30-31).

24 A este respecto, cabe decir que en los archivos y bibliotecas consultados no hemos localizado material gráfico (planos o fotografías) relativo a las instalaciones de este recinto (a excepción de la casa de baños) ni tampoco información sobre el proceso de su implementación. Probablemente su diseño fue ejecutado (o al menos supervisado) por el arquitecto municipal Segundo Díaz.

25 Este estuvo activo entre 1875 y 1880 aproximadamente, para dar cabida a agrupaciones artísticas muy modestas. Tenía una sola planta, con un patio recorrido por distintos tipos de asientos (Martínez, 2003: 630).

26 El restaurant y el café estaban a cargo del propietario del café Universal (paseo de la Independencia, n. ${ }^{\circ}$ 14) (Vázquez, 2015: 60).

27 En 1873, este maestro de obras fue nombrado ayudante primero del arquitecto municipal de Zaragoza (El Diario de Zaragoza, 3 de marzo de 1873: 3).

28 (AMZ Zaragoza, 1880). Referencia de esta figura: AMZ_1-9-6_0000481-1880_0014.

29 En estas fechas, esta compañía también actuaba en otros lugares como en el Circo de Price de Madrid (El Diario oficial de avisos de Madrid, 1 de junio de 1877: 7).

30 En 1871, durante el breve reinado de Amadeo de Saboya, tuvo lugar en el Congreso una deliberación sobre la Asociación Internacional de Trabajadores, que por aquellas fechas comenzaba a inquietar al poder público. La discusión nació a consecuencia de haber sido interpelado el Ministro de la Gobernación por el diputado conservador Jove y Hevia acerca de si el Gobierno estaba dispuesto a adoptar las medidas necesarias contra la Internacional, anunciando un amplio debate sobre ella (en caso de que en un cierto plazo de tiempo no se tomara ninguna determinación en este sentido). La posición de las dos figuras más representativas de la política en estos años, Sagasta y Ruiz Zorrilla, se había definido ya respecto de este punto: el primero citado había comunicado que estaba decidido a no permitir el establecimiento de la asociación; el segundo, siendo Presidente del Consejo de Ministros, había tenido -en opinión de Jove y Hevia- complacencias en dicha Internacional. Cuando ocho días después, el 14 de octubre de 1871, surgió de nuevo este asunto, comenzó a manifestarse la existencia de un núcleo tendente a impedir que la Internacional se declarase fuera de ley (Suárez, 1944: 484-492).

31 En estas fechas, Mariano Royo era el dueño del dominio directo de esta finca (AMZ Zaragoza, 1885).

32 Es una zona situada a la izquierda de la confluencia de la avenida de San José y el Canal Imperial.

33 Para el estudio de esta quinta de recreo, consúltese (Bosqued, 2017).

34 Referencia de esta figura: AMZ_4-2_0072_0001. Este plano muestra que el velódromo era colindante a la fábrica de camas de Miguel Irisarri que, a su vez, estaba próxima a la finca de Miguel Hipólito de Val (AMZ Zaragoza, expediente n. ${ }^{\circ}$ 1.024, 1896).

35 En estos momentos, Ramón Valenzuela era el presidente de la Sociedad Velocipédica Zaragozana.

36 Referencia de la figura 7: AMZ_1-9-6_0000532-1896_0004.

Por su parte, la figura 8 es una tarjeta postal que forma parte de una colección de la que se hicieron varias ediciones, aproximadamente entre 1920 y 1925, todas impresas en fototipia en tonos verdosos y azulados oscuros. Dimensiones: 8,8 x 13,8 cm. Pertenece a la colección de Luis Serrano Pardo, a quien deseamos expresar nuestra gratitud por la concesión de esta imagen.

La figura 9 es una tarjeta postal que fue editada por Ángel Toldrá Viazo, de Barcelona. Integra un conjunto de tarjetas postales sobre el Colegio del Salvador de Zaragoza, que se publicó entre 1900 y 1918 (atendiendo a las fechas escritas en ellas). Esta colección se conserva en el Archivo del Colegio del Salvador, Zaragoza (ACS Zaragoza) (Caja 1, material fotográfico). En este punto, quiero expresar mi más sincero agradecimiento al sacerdote jesuita Mario Cuartero por facilitarme la consulta de los fondos de este archivo.

37 En 1895 se anunciaba en la prensa zaragozana el restaurant Lion d’Or, junto al café de París, en calle del Coso, n. 56 (El Diario de Zaragoza, 5 de enero de 1895: 3).

38 Heraldo de Aragón, Zaragoza, domingo 27 de mayo de 1923, «Campos Elíseos», p. 5.

39 En este recinto se alquilaban bicicletas y patines, estaban establecidos clubs deportivos del ramo y se colocaron puestos de tiro al blanco y de otras atracciones. En este contexto, es interesante mencionar que cerca de la piscina del campo de fútbol de Torrero se inauguró un nuevo velódromo el 27 de mayo de 1928, que pudo motivar la desaparición del antiguo (Heraldo de Aragón, 1 de mayo de 1928: 1).

40 A partir del año 1900 Zaragoza se transformó considerablemente. Comenzaron a proyectarse diversos ensanches que ampliaron un perímetro que se había mantenido durante siglos -cubrimiento del río Huerva y formación de la Gran Vía, ensanches de Miralbueno y Miraflores, etc.-; pequeños asentamientos de carácter semirrural situados en las proximidades de la ciudad comenzaron a ampliarse hasta unirse definitivamente a la misma -progresivo desarrollo de los barrios de Delicias, Torrero, Las Fuentes, etc.-y ambiciosos proyectos de reforma interior alteraron profundamente su antiguo trazado (Yeste, 1998: 20).

41 La actuación del arquitecto municipal Ricardo Magdalena Tabuenca (1849-1910) como urbanista y su proyecto de ensanche de la ciudad han sido analizados por Ascensión Hernández Martínez en sus estudios (2012: 141-151).

42 A este respecto, cabe decir que en 1916 fue inaugurado el Petit Park (llamado más tarde Saturno Park), un parque de atracciones que se levantó sobre una parte de los solares que había ocupado la Exposición Hispano-Francesa de 1908 y terrenos adyacentes en la antigua huerta de Santa Engracia, situada dentro del perímetro urbano. Su cierre se efectuó en 1925 (Vázquez y Carretero). 


\section{Bibliografía}

ALDAMA FERNÁNDEZ, Laura (2006), «El edificio Elíseos de Zaragoza: un ejemplo de la arquitectura monumental de Teodoro Ríos», Artigrama, n. 21 , pp. 633-654.

Archivo de Villa de Madrid (AVM Madrid), Secretaría, Sección 6, Caja 63, expediente n. ${ }^{\circ}$ 23: «Expediente relativo a sociedades de recreo, científicas y literarias, como también de los edificios destinados para espectáculos públicos existentes en 1864 ", 1865.

Archivo del Colegio del Salvador, Zaragoza (ACS Zaragoza), Sección Quinta Julieta, Caja 1, expediente n. ${ }^{\circ}$ : «Quinta Julieta. Compra de la Quinta y Planos», 1917.

Archivo Municipal Zaragoza (AMZ Zaragoza), Policía Rural, Caja 1.438, expediente n. ${ }^{\circ} 481$ : "Sebastián Viñals solicita permiso para establecer unos baños de agua corriente con las del río Huerva junto a los Campos Elíseos», 1880.

- Construcciones, Caja 1.442, expediente n. ${ }^{\circ} 869$ : «D. Francisco Pascual en nombre y representación de D. Miguel Hipólito de Val solicita permiso para ampliar el edificio contiguo a los llamados Campos Elíseos en el paseo de Torrero", 1882.

- Construcciones, Caja 1.540, expediente n. ${ }^{\circ} 703$ : «D. Mariano Royo, permiso para abrir una puerta y dos ventanas en la fachada del edificio llamado "Campos Elíseos" en el paseo de Torrero", 1885.

- Construcciones, Caja 979, expediente n. ${ }^{5}$ 532: «D. Antonio Bovio pide autorización para practicar obras en la fachada de los Campos Elíseos (paseo de Torrero) con el objeto de instalar un velódromo», 1896.

- Construcciones, Caja 984, expediente n. ${ }^{\circ}$ 1.024: «D. Miguel Irisarri solicita se le autorice para el derribo de la tapia y puerta de entrada de su finca próxima a los Campos Elíseos y colocación de una valla y para levantar nuevo edificio», 1896.

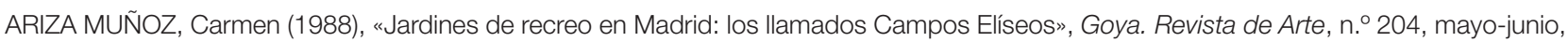
pp. 342-351.

BLASCO IJAZO, José (1955), La famosa Torre de Bruil, Librería General, Zaragoza.

- (1986), Los que fueron y los que son. Casi dos siglos de curiosa historia 1764-1945, El Día de Aragón, Zaragoza.

BORBÓN, L. A. (1896), «Barcelona ciclista», Barcelona Cómica, 25 de abril, p. 15.

BOSQUED, Pilar (2017), La Quinta Julieta de Zaragoza, Pilar Bosqued, Zaragoza.

BURKERT, Walter (1960), «Elysion», Glotta, vol. 39, n. ${ }^{\circ}$ 3-4, pp. 208-213.

CONLIN, Jonathan (ed.) (2013). The pleasure garden: from Vauxhall to Coney Island, University of Pennsylvania Press, Philadelphia.

CRUZ VALENCIANO, Jesús (2015), «Espacios públicos y modernidad urbana: la historia de los jardines de recreo en la España del siglo XIX», Historia Social, n. ${ }^{\circ} 83$, pp. 37-54.

CHANTRAINE, Pierre (1999), Dictionnaire étymologique de la langue grecque. Histoire des mots (nouvelle édition mise à jour), Klincksieck, París.

Diario Oficial de Avisos de Madrid (1858), 10 de abril, «Variedades», p. 4.

- (1858), 6 de mayo, «Variedades», p. 4.

- (1864), 22 de mayo, «Variedades», p. 4.

- (1864), 7 de junio, «Variedades», p. 4.

- (1864), 13 de junio, «Variedades», p. 4.

- (1864), 18 de junio, «Variedades», p. 4.

- (1864), 20 de junio, «Variedades», p. 4.

- (1865), 16 de febrero, «Variedades», p. 4.

- (1873), 10 de mayo, «Compras y ventas», p. 3.

- (1875), 6 de junio, «Generales», p. 4.

- (1875), 29 de septiembre, «Generales», p. 4.

- (1876), 19 de enero, «Subastas. Derribos», p. 3.

- (1877), 1 de junio, «Espectáculos», p. 7.

- (1878), 5 de noviembre, «Anuncios particulares», p. 4. 
El Áncora (1853), 11 de marzo, «Campos Elíseos», p. 1.128.

- (1853), 9 de abril, «Campos Elíseos», p. 160.

- 1853), 11 de abril, «Diario de avisos», pp. 178-179.

El Deporte Velocipédico (1896), 6 de mayo, «El ciclismo al día», pp. 2-3.

El Diario de Zaragoza (1868), 8 de octubre, «Gacetillas», p. 3.

- (1868), 11 de octubre de 1868, «Anuncios», p. 3.

- (1871), 24 de octubre, "Correspondencia particular de 'El Diario'», p. 1.

- (1873), 3 de marzo, «Gacetillas», p. 3.

- (1876), 12 de agosto, «Gacetillas», p. 3.

- (1876), 7 de octubre, «Campos Elíseos», p. 3.

- (1879), 24 de febrero, «Gacetillas», p. 2.

- (1880), 17 de octubre, «Espectáculos», pp. 1-2.

- (1880), 31 de diciembre, «Espectáculos», p. 2.

- (1883), 10 de julio, «Gacetillas», p. 2.

- (1891), 10 de octubre, «Crónica del día», p. 2.

- (1892), 4 de noviembre, "Crónica del día», p. 4.

- (1895), 5 de enero, p. 3.

- (1897), 29 de mayo, «Noticias locales», p. 6.

El Imparcial (1882), 7 de noviembre, «Los velocipedistas», p. 2.

El Liberal (1896), 12 de abril, «Velocipedismo», p. 3.

- (1896), 19 de abril, «Carreras de velocípedo en Zaragoza», pp. 2-3.

El Museo Universal (1864), 26 de junio, p. 205.

FERNÁNDEZ DE LOS RíOS, Ángel (1868), El futuro Madrid, paseos mentales por la capital de España, tal cual es y tal cual debe dejarla transformada la revolución (2. a ed.), Imprenta de la Biblioteca Universal Económica, Madrid.

FORCADELL ÁlVAREZ, Carlos (1997), Historia de Zaragoza. Zaragoza en el siglo XIX (1808-1908), Ayuntamiento, Servicio de Cultura: Caja de Ahorros de la Inmaculada, D.L., Zaragoza.

GRIMAL, Pierre (1981), Diccionario de mitología griega y romana, Paidós, Barcelona.

Heraldo de Aragón (1896), 4 de mayo, «El velódromo de los Campos Elíseos», p. 2.

- (1904), 24 de noviembre, «Ayer y hoy en el Colegio de El Salvador», p. 1.

- (1915), 2 de julio, «Noticias locales», p. 5.

- (1916), 4 de abril, «Mejora urbana. El proyecto de ensanche del puente sobre el río Huerva», p. 1.

- (1924), 1 de julio, «Las mejoras urbanas. Ayer se inauguraron oficialmente las obras de cubrimiento del Huerva», p. 1.

- (1928), 1 de mayo, «La inauguración de un velódromo», p. 1.

HERNÁNDEZ MARTíNEZ, Ascensión (1991-1992), «La planificación urbana en Zaragoza a comienzos del siglo XX: la apertura del paseo de Sagasta», Artigrama, n. ${ }^{\circ}$ 8-9, pp. 435-454.

- (2012), Ricardo Magdalena. Arquitecto municipal de Zaragoza (1876-1910), Institución «Fernando el Católico». Ayuntamiento de Zaragoza, Zaragoza.

La Época (1896), 3 de mayo, «Últimos telegramas. Nuevo velódromo», p. 3.

LÓPEZ-CORDÓN, María Victoria (1976), La revolución de 1868 y la República, Estudios de Historia Contemporánea Siglo XXI, Madrid. MARTÍNEZ HERRÁNZ, Amparo (1997), Los cines en Zaragoza, 1896-1936, Ayuntamiento de Zaragoza, Zaragoza.

- (2003), La arquitectura teatral en Zaragoza. De la Restauración borbónica a la Guerra Civil (1875-1939), Vol. II, Institución «Fernando el Católico", Zaragoza.

PRIETO GONZÁLEZ, José Manuel y RODRÍGUEZ ROMERO, Eva J. (1998), “'Caprichos' en el jardín. Ficción y realidad en la escenografía de los ámbitos de recreo público decimonónicos», Archivo Español de Arte, vol. LXXI, n. 281, octubre-diciembre, pp. 391-406. 
RÉPIDE, Pedro de (2002), Madrid visto y sentido por Pedro de Répide, Ediciones La Librería, Madrid.

RÓDRíGUEZ ROMERO, Eva J. y PRIETO GONZÁLEZ, José Manuel (1997), «Haciendo el jardín de las Delicias. Ficción y realidad en relación a los ámbitos de recreo público decimonónicos», Archivo Español de Arte, vol. LXX, n. ${ }^{\circ}$ 280, octubre-diciembre, pp. $398-418$.

RUIZ MARíN, Julián (1998), Memoria de las calles de Zaragoza, Tomo III, Librería General, S.A., Zaragoza.

SÁNCHEZ MENCHERO, Mauricio (2009), "Cinco cuadros al fresco. Los jardines de recreo en Madrid (1860-1890)», Culturales, vol. V, n. ${ }^{9}$, enero-junio, pp. 141-168.

SUÁREZ VERDEGUER, Federico (1944), «La Internacional en las Cortes de 1871», Revista de estudios políticos, n. ${ }^{\circ}$ 15-16, pp. 484-492.

URÍA, Jorge (2001), «Lugares comunes para los ciudadanos. Breves apuntes sobre el jardín español del siglo XIX», Pandora, n. ${ }^{\circ}$, pp. 245-266.

VÁZQUEZ ASTORGA, Mónica (2015), Cafés de Zaragoza. Su biografía, 1797-1939, Institución «Fernando el Católico», Zaragoza.

- (2018), «\|l Tivoli di Firenze (Italia): un parco divertimenti ottocentesco», en BIEDERMANN, Anna, LÁZARO SEBASTIÁN, Francisco J. y SANZ FERRERUELA, Fernando (coords.), En los márgenes de la ciudad, del arte y de la crítica, Prensas de la Universidad de Zaragoza, Zaragoza, pp. 75-91.

VÁZQUEZ ASTORGA, Mónica y CARRETERO CALVO, Rebeca (en prensa), «Instantáneas de un 'paraíso de recreo' en Zaragoza: el desaparecido Petit Park -luego Saturno Park- (1916-1925)», en Actas de las II Jornadas sobre Investigación en Historia de la Fotografía, 1839-1939: Un siglo de fotografía, Zaragoza.

VILLORO I MARTíN, Joan (1984), Guia dels espais verds de Barcelona. Aproximació histórica, Col·legi Oficial d'Arquitectes de Catalunya. Delegació de Barcelona i Caixa de Pensions «La Caixa», Barcelona.

YESTE NAVARRO, Isabel (1998), La reforma interior. Urbanismo zaragozano contemporáneo, Institución «Fernando el Católico», Zaragoza.

- (2016), «La imagen perdida: Ios hotelitos de la Plaza de Aragón en Zaragoza», Artigrama, n. 31, pp. 391-419. 